\title{
Forming field distribution in airgap of magnetic circuit
}

\author{
Paweł Stec \\ Gdańsk University of Technology \\ Department of Automatic Control of Electrical Drives \\ p.stec@ely.pg.gda.pl
}

\begin{abstract}
The airgap feature in magnetic circuit. Size of the airgap decide of many features of electrical motors or electromagnetic transducer. Forming ability of field distribution give engineers opportunity to design high efficiency electrical drives. Today engineers have two way to design electrical drives - change shape of stator of electrical motors or use voltage or current converter.
\end{abstract}

\section{Introduction}

For many years people have used electrical energy. The simplest use is electromagnet in doorbell. The airgap in magnetic circuit can obtain a strong magnetic field with high degree of homogenity, what is important in more complicated use of electromagnetic energy - electrical motors. From the beginning engineers have been trying to design high reliability and high efficiency electrical drives. Achievements of generations allowed us to make electrical drives with efficiency around 98-99\%, but the highest efficiency was obtained by the highest power machines working with nominal speed. Efficiency of electrical drives is less for lower speed, therefore electrical drives work with power electronics inverter. This connection allowed to good dynamics features and high efficiency for wide range of velocity.

\section{Airgap}

Size of the airgap decides about features of electrical machines. Also axial dimension of airgap and overloading are bigger, but the maximal mechanical torque are lover. When Indirectly connecting induction motor to grid, through voltage (Fig.1) or current the magnetizing current is bigger, then airgap is growing. So as before once the axial dimension of airgap was about $1 \mathrm{~mm}$, today for the same power this dimension is about $0.25 \mathrm{~mm}$.

\section{Field distribution}

Field distribution in airgap of electrical machines can be forming by:

- properly choice number of slots,

- proper schema of windings,

- choice type of motors,

- choice source of energy,

- method of control.

Some of those methods are mutually dependent. Number of slots is depending on the dimension of drive and on the numbers of phase of source. The schema of windings is depending on number of slots and on the maximum speed of rotor.

The method of control is depending on source of energy and on type of motors.

\section{Three phase squirrel cage induction motor}

Three phase squirrel cage induction motor is used in typical application for variable speed drives. This drives has minimal number of phase to generate rotating magnetic field and is prepared for work with three phase power gird. Directly connecting induction motor to grid allowed to work only with synchronous rotating magnetic field.

(Fig.2) source inverter allowed to work with wide range of speed. 


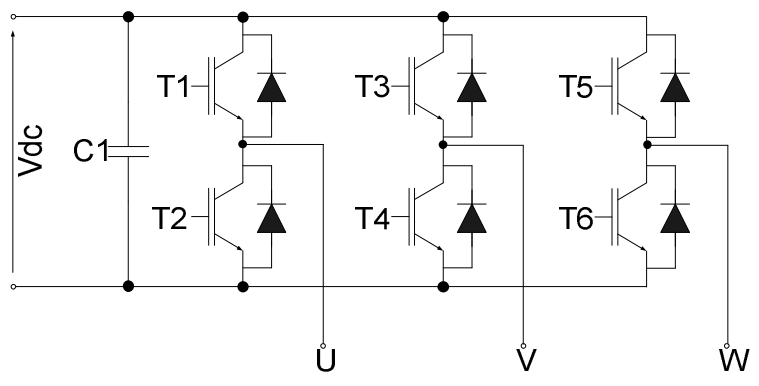

Fig. 1. Three phase voltage source inverter L1

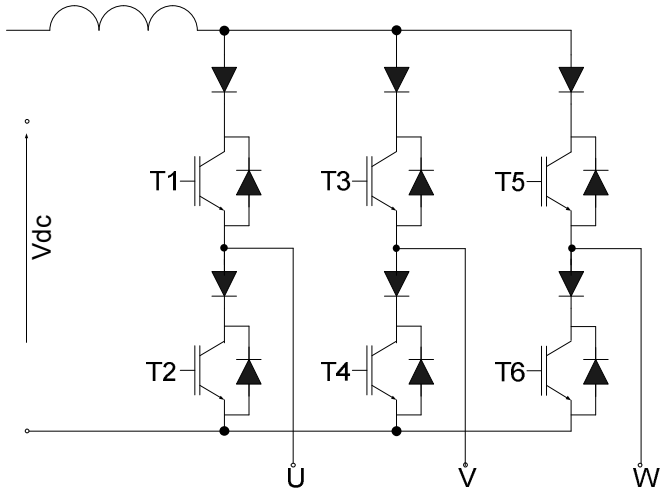

Fig. 2. Three phase current source inverter

Three phase 36 slots 4 poles $5 \mathrm{~kW}$ induction motor connected directly to grid has quasisinusoidal field distribution (Fig.4)

Distortions are depending on dimensions and shapes of slots. On the waveform of magnitude of magnetic induction (Fig.6) we can find numbers of distortions derived from slots, and the number of distortions are equal numbers of slots.

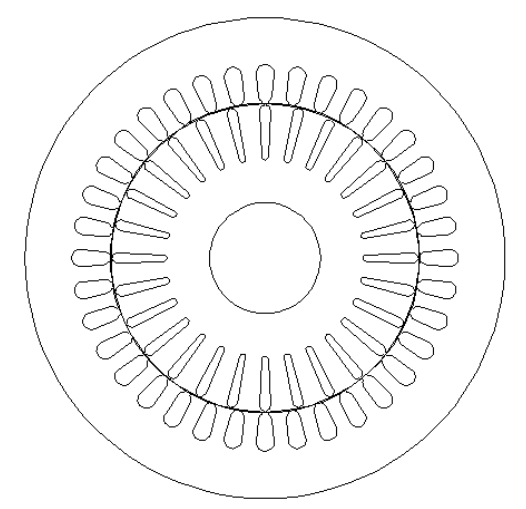

Fig. 3. The transverse section of three phase squirrel cage induction motor

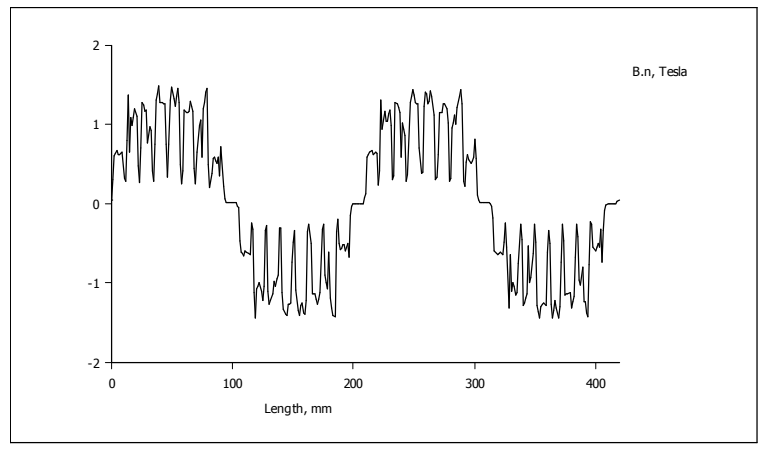

Fig. 4. Distribution of magnetic induction in airgap of 3-phase induction motor

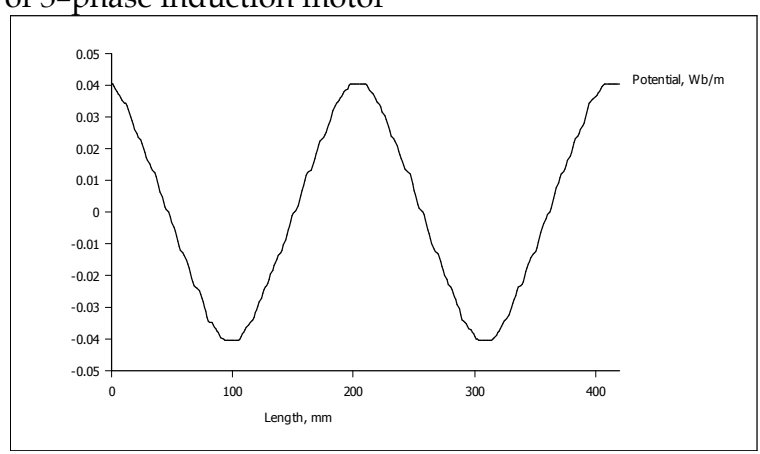

Fig. 5. Distribution of magnetic potential in airgap of 3-phase induction motor

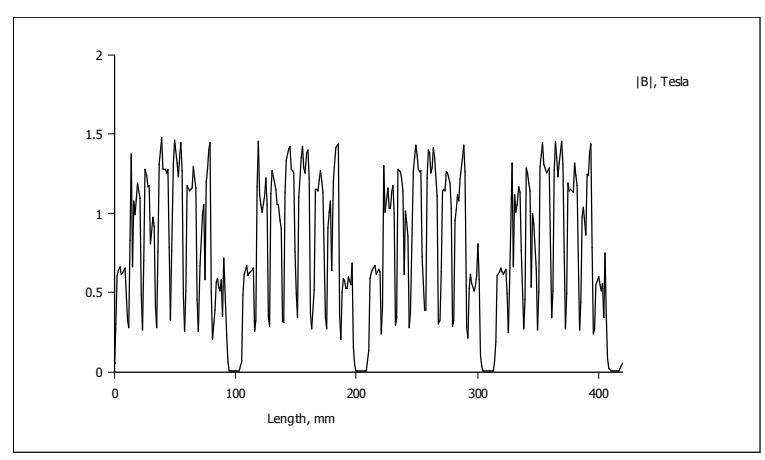

Fig. 6. Distribution of magnitude of magnetic induction in airgap of 3-phase induction motor

This results (Fig.4, Fig.5, Fig.6) was obtain by using Finite Element Method. Design of transverse cross-section was prepared by the CAD program and next the area is discretizating to the area of small triangles. ( Fig. 7) 


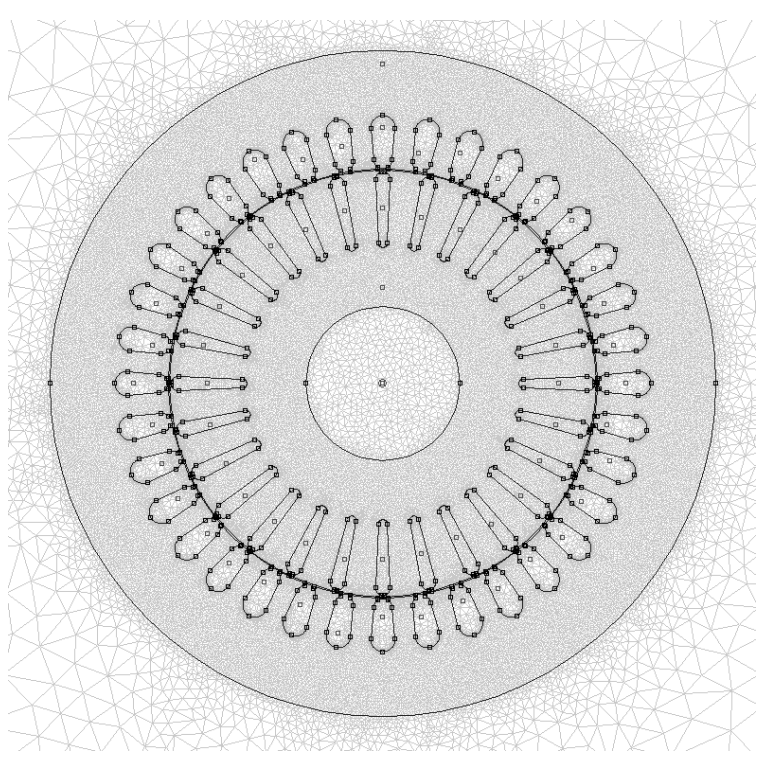

Fig. 7. The transverse section of induction motor with grid of finite element method

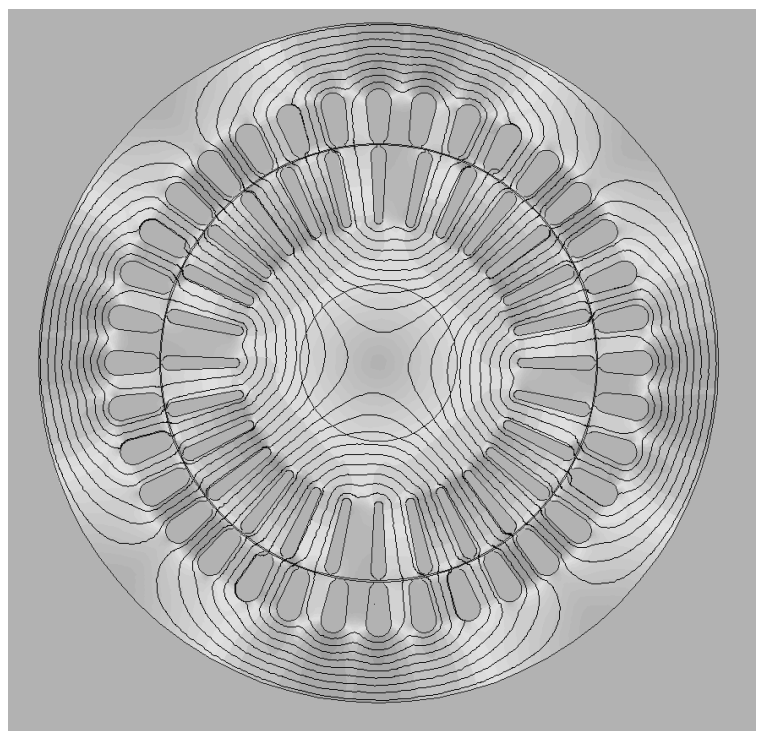

Fig. 8. The field distribution with line of magnetic field for 3-phase induction motor

\section{Nine phase squirrel cage induction motor}

The induction motor with more phase than three are not popular machines in industry applications. High cost of nonstandard machines are market barrier for ventures technology. However in specializing applications are unreplaceable $[1,2,3]$. In a multi-phase machine drive system, more than three phase windings are housed in the same stator of the electric machine, and the current per phase in the machine is, thereby reduced. In addition to enhancing power rating, it is also believed that drive systems with such multiphase redundant structure will improve the reliability at the system level. In particular, unlike in normal three-phase system, the loss of one phase in multi-phase machine drive system does not prevent the machine from starting and running. In addition, the advantages of multiphase are reducing the amplitude and increasing the frequency of torque pulsation, reducing the rotor harmonic currents losses, lowering the dc link current harmonics etc[4].

Below was shown result of magnetic field simulation for nine-phase four poles induction motor (Fig. 9, Fig.10, Fig.12) and for nine-phase twelve poles induction motor (Fig. 13, Fig.15, Fig.14).

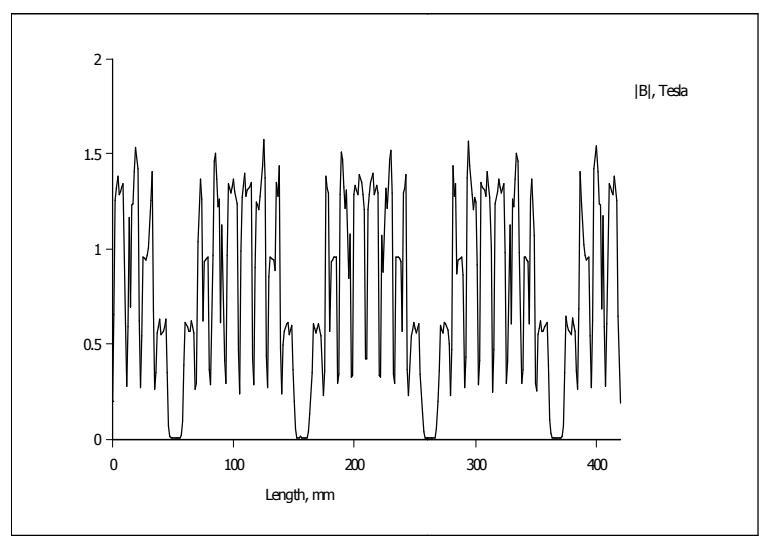

Fig. 9. Distribution of magnitude of magnetic induction in airgap of 9-phase 4 poles induction motor

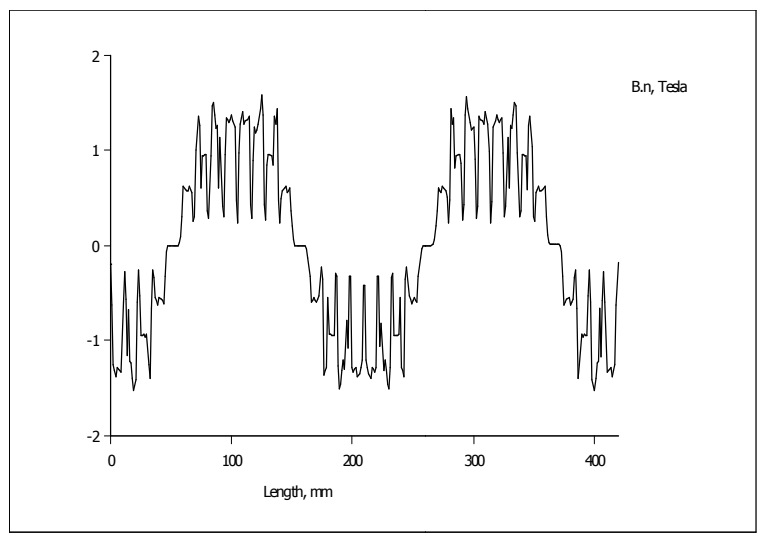

Fig. 10. Distribution of magnetic induction in airgap of 9-phase 4 poles induction motor 


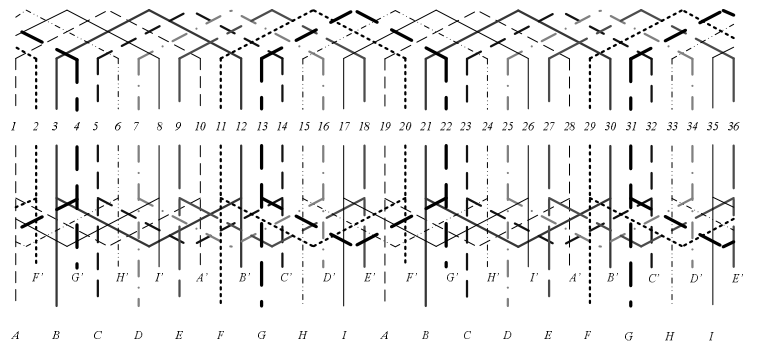

Fig. 11. Windings of 9-phase induction motor

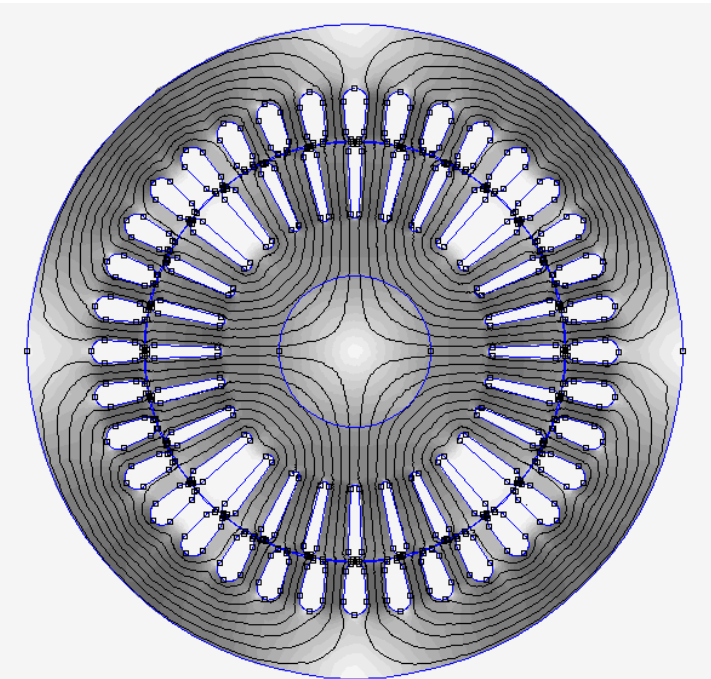

Fig.12. The field distribution with line of magnetic field for 9-phase 4 poles induction motor

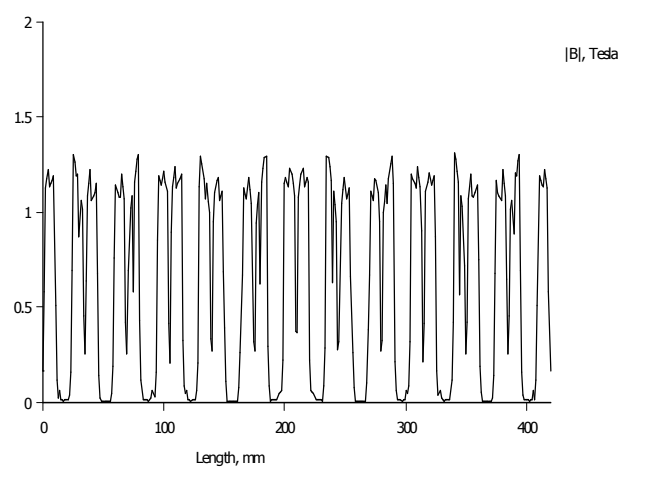

Fig. 13. Distribution of magnitude of magnetic induction in airgap of 9-phase 12 poles induction motor

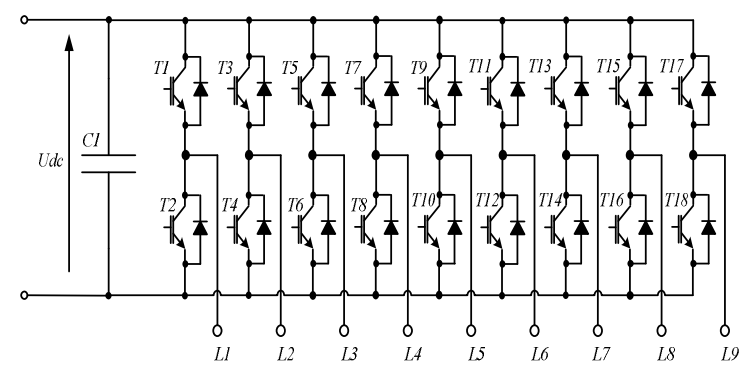

Fig. 14. Topology of 9-phase voltage source inverter

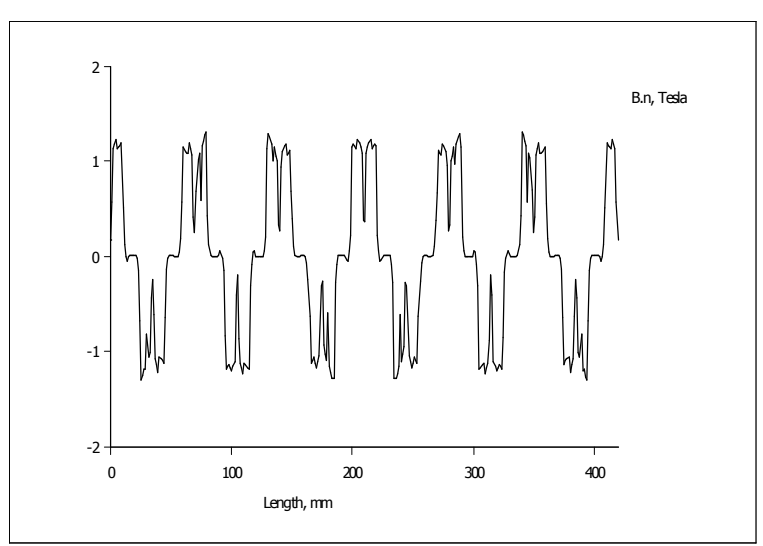

Fig. 15. Distribution of magnetic induction in airgap of 9-phase 12 poles induction motor

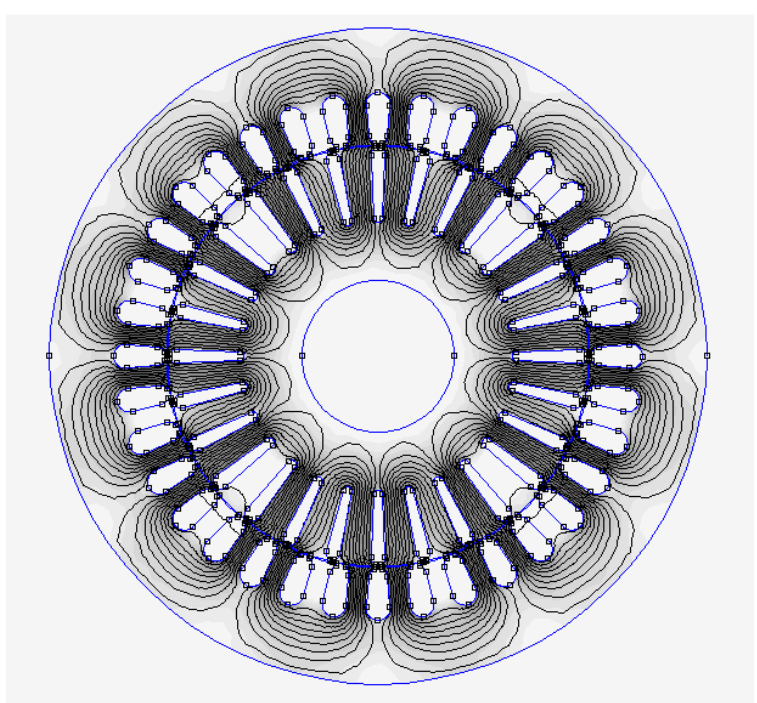

Fig.16. The field distribution with line of magnetics field for 9-phase 14 poles induction motor

The simulation was based on project of nine phase $4 \mathrm{~kW}$ induction motor, which was designed from stator of $5 \mathrm{~kW}$ induction motor - Sg132. For this stator was designed nine phase windings (Fig. 11). Also motor was prepared to work with nine phase voltage source inverter (Fig. 14). The twelve magnetic poles was obtain by generating third harmonics of current. 


\section{Fifteen phase squirrel cage induction motor}

Fifteen phase induction motor can not be designed from typical stator of 3-phase induction motor, just like in nine phase motor. To build 15-phase induction motor is required min. 30 slots stator. For simulation of fifteen phase induction motor was used stator of SZUDf56 induction motor [5]. On figure (Fig.17, Fig.18, Fig.19) was shown results of simulation. On figure (Fig. 20) was shown the winding designed for 15phase induction motor performed to work with 15-phase voltage source inverter (Fig. 21)

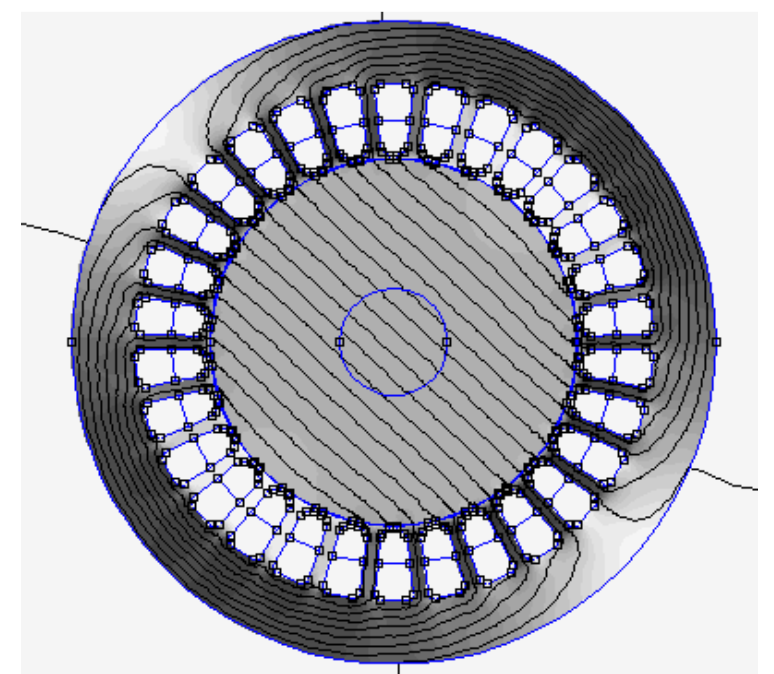

Fig.17. The field distribution with line of magnetics field for 15-phase 2 poles induction motor

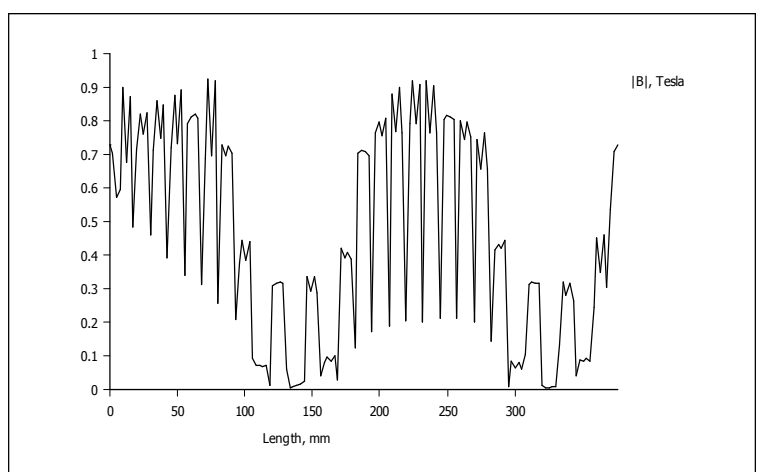

Fig. 18. Distribution of magnitude of magnetic induction in airgap of 15-phase 2 poles induction motor

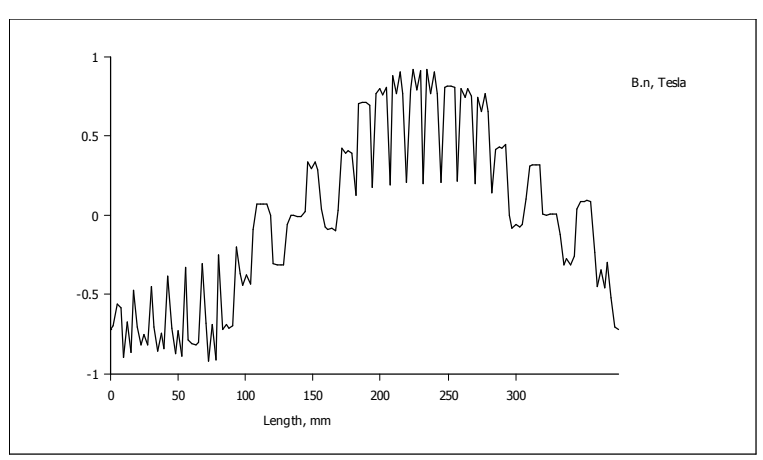

Fig. 19. Distribution of magnetic induction in airgap of 15-phase 2 poles induction motor

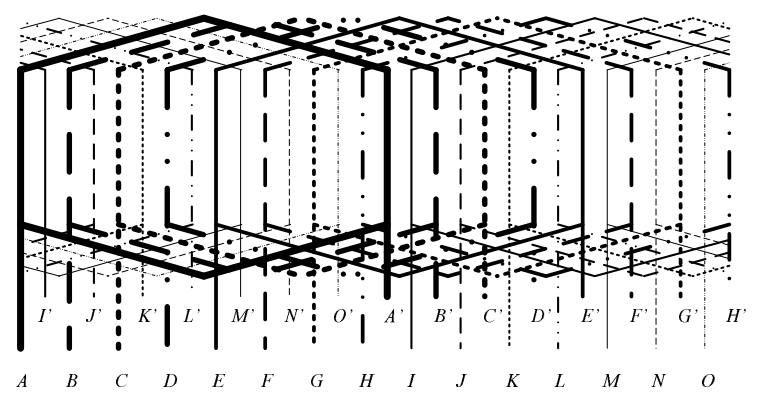

Fig. 20. Windings of 15 -phase 2 poles induction motor

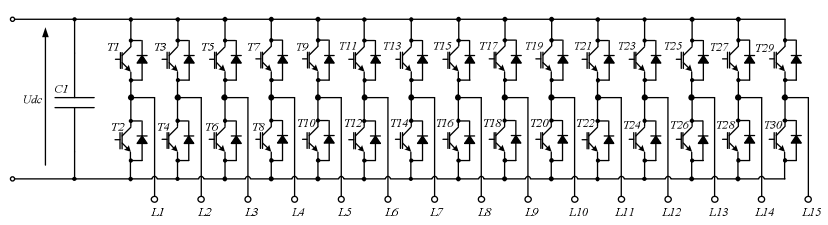

Fig. 21. Topology of 15-phase voltage source inverter

\section{Conclusion}

Field distribution in airgap of induction motor can be forming by many methods. In paragraphs was shown that multiphase induction motor have good field distribution and their features can be obtain by special design of stator ( 15 phase motor), by supply voltage source inverter or by choice the number of phase.

\section{REFERENCES}

[1] S. Smith, Developments in power electronics, machines and Drives, IEE Power Eng. Journal, nr 1 (2002), 13-17

[2] S. Mantero, A. Monti, S. Spreafico, DC-bus voltage control for double star asynchronous fed drive under fault conditions, Proc. IEEE Power Elec. Spec. Conf. PESC, 2000, 533 - 538. 
[3] R. Bojoi, M. Lazzari, F. Profumo, A. Tenconi, Digital field oriented control for dual-three phase induction motor drives, IEEE Trans. on Ind. Appl., 39 (2003), nr 3, 752-760

[4] G. Singh, Multi-phase induction machine drive research-a survey, Electric Power Systems Research, 2002, vol.61, Issue 2,139-147

[5] P. Stec, M. Morwiec, Analiza pracy silnika indukcyjnego 15 fazowego z przekształtnikiem, Wiadomości elektrotechniczne,(6)2010,

[6] M. van der Duijn Schouten, B. Gordon, R.A. McMahon, Multipjase induction motors for integrated drives, Ninth Internafional Conference on Elecfrical Machines and Drives, 1999

[7] F. Terrien, S. Siala, P. Noy, Multiphase induction motor sensorless control for electric ship propulsion, Alstom Power Conversion Marine E Offshore.

[8] S. Lu, K. Corzine, Multilevel multiphase propulsion driver. IEEE Electric ship technologies symposium, 2005 